\title{
Prevention of Ni Ti Instrument Fracture: A Systematic Review
}

\author{
Dr. Jyoti Jain ,M.D. $S^{1,}$ Dr. Ramesh Chandra ${ }^{2,}$ Dr. Shailja Singh ${ }^{3,}$ Dr. Manjusha \\ Mohan $^{4,}$ Dr. Supratim Tripathi ${ }^{5}$, Dr. Sanjay Jaiswal ${ }^{6}$ \\ ${ }^{1,6}$ Senior lecturer Department of Conservative dentistry \& Endodontics, Career post graduate institute of dental \\ sciences, Lucknow, U.P. India \\ ${ }^{2}$ ProfessorDepartment of Conservative dentistry \& Endodontics, Career post graduate institute of dental \\ sciences, Lucknow, U.P. India \\ ${ }^{3,4,5}$ Reader ${ }^{2}$ ProfessorDepartment of Conservative dentistry \& Endodontics, Career post graduate institute of \\ dental sciences, Lucknow, U.P. India
}

\begin{abstract}
A successful root canal treatment depend upon so many factor but the most important factor which determine the efficacy of all subsequent procedures such as debridement, medicament delivery, and obturation is mechanical preparation of root canal system .Traditionally stainless steel files were used, but with the introduction of nickel titanium (NiTi) alloys significantly broadened the instrument design. So many factors affect the separation of nickel titanium instrument and the rate of separation of nickel titanium is $30-60 \%$ and breakage rate $9.4 \%$. The aim of this review article is to discuss the methods that prevent the separation of nickel titanium instrument and improve the success of root canal treatment to save teeth.
\end{abstract}

Keywords: Nickel titanium instrument, Separation, Reciprocation

\section{Introduction}

A successful root canal treatment depend upon so many factor but the most important factor which determine the efficacy of all subsequent procedures such as mechanical debridement ,medicament delivery, and obturation is root canal preparation.(1)Traditionally stainless steel files were used, but with introduction of nickel titanium (Ni-Ti) alloys significantly broadened the instrument design .Ni-Ti instrument provides greater flexibility which speed up the preparation of canal and reduce fatigue to the dentist, decreased canal transportation and ledging but the main problem with $\mathrm{NiTi}$ instrument is separation of instrument within the canal . The rate of separation of nickel titanium is $30-60 \%$ and breakage rate $9.4 \% .(2,3)$ There are two reasons which explain the fracture/separation of $\mathrm{Ni} \mathrm{Ti}$ instrument:

1. Torsional fracture: When the tip of the instrument gets locked into a root canal, stops rotating and breaks off.

2. Cyclic fatigue: When an instrument is rotated continuously around a curve and catastrophic opening of surface micro-cracks occurs.

So this review focused on the methods that reduce the chances of separation of nickel titanium instrument.

\section{Review:}

A web-based research on MEDLINE (www.pubmed.gov) was done. To limit our research to relevant articles, the search was filtered using terms "Fracture of nickel titanium instrument in endodontics". I had found 177 articles in which 24 articles were chosen to get the desired knowledge update. This review article screened about 24 articles and then the relevant information was compiled.

\section{Methods that reduce the fracture of NI-TI instrument:}

1. Thermomechanical treatment of nickel-titanium instruments: The mechanical performance of NiTi alloys is sensitive to their microstructure and associated thermomechanical treatment. Heat treatment or thermal processing is one of the most fundamental approaches toward adjusting the transition temperature in $\mathrm{NiTi}$ alloy, which affects the fatigue resistance of NiTi endodontic files. The newly developed NiTi instruments made from controlled memory wire, M-Wire (Dentsply Tulsa Dental Specialties, Tulsa, OK), or R-phase wire represent the next generation of NiTi alloys with improved flexibility and fatigue resistance and the resistance to cyclic fatigue and torsion.(4)

2. Low-torque endodontic motors in root canal instrumentation: If a high-torque motor is used, the instrument-specific limit-torque (fracture limit) is often exceeded, thus increasing the chances of instrument fracture within the canal. A possible solution to this problem is to use a low-torque endodontic motor which operates below these values. If the torque is set just below the limit of elasticity for each instrument, the risk of fracture is markedly reduced.(5) 
3.Reciprocation:In 1985 manual reciprocation (clockwise and anticlockwise Movements) used for the preparation of root canals with stainless steel files but this technique is time consuming and produces a high level of procedural errors. In 1964 automated reciprocation was introduced with the Giromatic utilising stainless steel files moving with a 90 degree clockwise and anticlockwise motion but this technique causes greater procedural errors than hand filing .(6) In 2008 this concept of reciprocating files was re-introduced with ProTaper and this was shown to be as effective at cleaning around root canals and to extrude similar amounts of apical debris .(7)In 2011 a re-emergence of reciprocation and development of single file NiTi preparation systems such as Reciproc (VDW) and Wave One (DentsPly) single file systems provide reciprocating movement in an anticlockwise direction up to 130 degrees, followed by a clockwise releasing movement of 50 degrees. This means that each instrument takes three rotations to complete a full 360 degree rotation which is lower than the elastic limit of the instrument so the chances of fracture is low. Neelakantan P et al compare the cyclic fatigue of a rotary (One Shape) and reciprocating (Reciproc) single file system in a simulated S-shaped canal in static and dynamic models and the result showed that single file reciprocating system (Reciproc) had a longer fatigue life than the single file rotary system (One Shape).(8)Vadhana $\mathrm{S}$ et al evaluate and compare the cyclic fatigue resistance of RaCe (FKG Dentaire, La Chaux-de-Fonds, Switzerland) and Mtwo (VDW, Munich, Germany) rotary files in continuous rotation and reciprocating motion and result showed that Mtwo and $\mathrm{RaCe}$ rotary instruments showed a significantly higher cyclic fatigue resistance nreciprocating motion compared with continuous rotation motion.(9)Gavini G evaluate the resistance to flexural fatigue of Reciproc R25 nickeltitanium files, $25 \mathrm{~mm}$, used in continuous rotation motion or reciprocation motion, in dynamic assays device and results showed that the reciprocation motion improves flexural fatigue resistance in nickel - titanium instrument Reciproc R25 when compared with continuous rotation movement.(10)

4. Irrigants: Irrigants play a very important role in prevention of instrument fracture within the root canal. Under the normal use, when the instruments reach near their endurance limit, failure may occur. In addition to this when the temperature of files increases due to the instrument's thermodynamical situation that will also promote instrument failure. (11) Current studies suggested that the irrigation solutions which are used during root canal preparation can decrease the instrument temperature and also act as a heat absorber so that it decrease the chances of instrument failure and also suggested that $\mathrm{NaOCl}$ irrigation solution is more suitable in comparison with water and air conditions. Mousavi SA et al. determine the effect of irrigation on temperature and failure of Ni-Ti rotary files and concluded that the fatigue life of Ni-Ti rotary files instruments is longer in liquid media than in air. (12)

5. Sterilization: Autoclave sterilization was suggested to extend the life of nickel-titanium rotary endodontic instruments by reducing the effect of cyclic fatigue due to its ability of heat treatment. Shen $\mathrm{Y}$ et al. studied the effect of environment on fatigue failure of controlled memory wire nickel-titanium rotary instruments and the result was concluded that heat treatment as a result of autoclave sterilization does not extend the useful life of nickel-titanium instruments.(13)Mize SB et al. evaluated the effect of repeated sterilization cycles in dry oven or autoclave, on the mechanical behaviour and fatigue resistance of rotary endodontic Ni-Ti instruments and the result concluded that Changes in the mechanical properties of Ni-Ti endodontic instruments after five cycles of commonly used sterilization procedures were insignificant so that the sterilization procedures are safe as they produced a significant increase in the fatigue resistance of the instruments.(14)Paul B et al. in 2011 studied the effect of multiple autoclave cycle effects on cyclic fatigue of GT Series X file and Twisted Files and the result showed that The GT Series X files showed no significant difference in mean cycle failure (MCF) for experimental( autoclaved)versus control(not autoclaved) files. Twisted Files showed no significant difference in MCF between experimental and control groups. However, the Twisted Files showed a significantly lower MCF compared with the controls.(15)Gianluca plotino et.al. evaluated the the effect of autoclave sterilization on cyclic fatigue resistance of rotary endodontic instruments made of traditional and new nickel-titanium (NiTi) alloys and the result concluded that repeated cycles of autoclave sterilization do not seem to influence the mechanical properties of NiTi endodontic instruments except for the K3 XF prototypes of rotary instruments that demonstrated a significant increase of cyclic fatigue resistance. (16)

6. Rotational speed: Studies suggested that lower rotational speeds (150 to $250 \mathrm{rpm}$ versus $300 \mathrm{rpm}$ and higher) will help avoid instrument separation and deformation. $(17,18,19,20)$ A report concluded that a speed of $150 \mathrm{rpm}$ was associated with delayed breakage because of cyclic fatigue when compared to 350 rpm.(21)Another study concluded that rotational speed was not a significant factor affecting cyclic fatigue failure. Confusing this matter, most manufacturers recommend rotational speeds in the range of 150 to 350 $\mathrm{rpm}$. The importance of rotational speed in regard to instrument failure requires further study. Rotary files can be used to remove gutta-percha during re-treatment. $(22,23)$ The use of $1,500 \mathrm{rpm}$ was found to be associated with more rapid and effective removal of gutta-percha than either 350 or $700 \mathrm{rpm}$. At this higher rpm, there was also less instrument separation.(24)It is important to note that when using rotary files at this speed, the file should have minimal if any engagement of the canal walls and should be placed completely into the gutta- 
percha. Rotating a nickel titanium file at this speed at a location below the middle third of any canal is to be avoided.

\section{Conclusion}

1. The newly developed Ni-Ti instruments that are made from controlled memory wire, M-Wire or R-phase wire which represent the next generation of NiTi alloys showed improved flexibility and fatigue resistance and the resistance to cyclic fatigue and torsion so that the chances of Ni-Ti instrument fracture highly reduced.

2. Torque is set just below the limit of elasticity for each instrument so that the risk of fracture is markedly reduced.

3. Reciprocation motion improves flexural fatigue resistance in nickel-titanium instrument compared with continuous rotation movement and reduces the risk of fracture.

4. Irrigation solutions which are used during root canal preparation can decrease the instrument temperature and also act as a heat absorber so that it decreases the chances of instrument failure.

5. Changes in mechanical properties of $\mathrm{Ni}-\mathrm{Ti}$ endodontic instruments after sterilization procedures were insignificant so that the sterilization procedures are safe as they produced a significant increase in the fatigue resistance of the instruments

6. Recommended rotational speed $150-350 \mathrm{rpm}$ avoid instrument separation and deformation.

My opinion: Fracture of Ni-Ti rotary instrument complicates the progress, and compromises the prognosis of endodontic treatment so if we are using a appropriate methods that reduces the cyclic fatigue and torsional fracture of the instrument, the success rate of endodontic treatment greatly increased.

\section{References}

[1]. Peters O A. Current challenges and concepts in the preparation of root canal systems: a review. J Endod 2004; 30: 559-567.

[2]. Szep S, Gerhardt T, Leitzbach C, et al. Preparation of severely curved simulated root canals using engine-driven rotary and conventional hand instruments. Clin Oral Investig. 2001;5(1):17-25.

[3]. Baumann MA, Roth A. Effect of experience on quality of canal preparation with rotary nickel-titanium files. Oral Surg Oral Med Oral Pathol Oral Radiol Endod. 1999;88(6):714-718.

[4]. Shen Y, Zhou HM, Zheng YF, Peng B, Haapasalo M. Current challenges and concepts of the thermomechanical treatment of nickel-titanium instruments.

[5]. Gambarini G. Rationale for the use of low-torque endodontic motors in root canal instrumentation. Endod Dent Traumatol. 2000 Jun;16(3):95-100.

[6]. Weine F S, Kelly R F, Bray K E. Effect of preparation with endodontic handpieces on original canalshape. J Endod 1976; 2: 298303.

[7]. De-Deus G, Brandao M C, Barino B et al. Assessment of apically extruded debris produced by the singlefile ProTaper F2 technique under reciprocatingmovement. J Endod 2010; 110: 390-394.

[8]. Neelakantan P, Reddy P, Gutmann JL. Cyclic fatigue of two different single files with varying kinematics in a simulated doublecurved canal.

[9]. Vadhana S, SaravanaKarthikeyan $\mathrm{B}^{1}$, Nandini $\mathrm{S}^{2}$, Velmurugan $\mathrm{N}^{1}$.J Endod. Cyclic fatigue resistance of RaCe and Mtwo rotary files in continuous rotation and reciprocating motion.2014 Jul;40(7):995-9. doi: 10.1016/j.joen.2013.12.010. Epub 2014 Mar 6.

[10]. Gavini G, Caldeira CL, Akisue E, Candeiro GT, Kawakami DA. Resistance to flexural fatigue of Reciproc R25 files under continuous rotation and reciprocating movement. J Endod. 2012 May;38(5):684-7. doi: 10.1016/j.joen.2011.12.033. Epub 2012 Jan 24.

[11]. McKelvey AL, Ritchie RO. On the temperature dependence of the superelastic strength and the prediction of the theoretical uniaxial transformation strain in Nitinol. Philo Mag. 2000;80:1759-68.

[12]. Mousavi SA, Kargar-Dehnavi V, Mousavi SA. Dent Res J (Isfahan). A novel approach to determine the effect of irrigation on temperature and failure of Ni-Ti endodontic rotary files. 2012 May;9(3):281-7.

[13]. Shen Y, Qian W, Abtin H, Gao Y, Haapasalo M.Effect of environment on fatigue failure of controlled memory wire nickel-titanium rotary instruments. J Endod. 2012 Mar;38(3):376-80. doi: 10.1016/j.joen.2011.12.002. Epub 2012 Jan 9

[14]. Mize SB, Clement DJ, Pruett JP, Carnes DL Jr Effect of sterilization on cyclic fatigue of rotary nickel-titanium endodontic instruments. J Endod.. 1998 Dec;24(12):843-7.

[15]. Paul B. Hilfer, DDS,Brian E. Bergeron, DMD, Michael J. Mayerchak, DMD Howard W. Roberts, DMD, MS ${ }^{\dagger}$, Billie G. Jeansonne, DDS, PhD. Multiple Autoclave Cycle Effects on Cyclic Fatigue of Nickel-Titanium Rotary Files Produced by New Manufacturing Methods .journal of endodontics. Volume 37, Issue 1, January 2011, Pages 72-74.

[16]. Gianluca Plotino, Alberto Costanzo,Nicola M. Grande, Renata Petrovic, Luca Testarelli, Gianluca Gambarini. Influence of Autoclave Sterilization on the Cyclic Fatigue of New Nickel-Titanium Rotary Instruments.Journal of EndodonticsVolume 38, Issue 2, February 2012, Pages 222-225.

[17]. Dietz DB, Di Fiore PM, Bahcall JK, et al. Effect of rotational speed on the breakage of nickel-titanium rotary files. J Endod. 2000;26(2):68-71.

[18]. Gabel WP, Hoen M, Steiman HR, et al. Effect of rotational speed on nickel-titanium file distortion. J Endod. 1999;25(11):752-754

[19]. Li UM, Lee BS, Shih CT, et al. Cyclic fatigue of endodontic nickel titanium rotary instruments: static and dynamic tests. J Endod. 2002;28(6):448-451.

[20]. Yared GM, Bou Dagher FE, Machtou P. Influence of rotational speed, torque and operator's proficiency on ProFile failures. Int Endod J. 2001;34(1):47-53.

[21]. Martin B, Zelada G, Varela P, et al. Factors influencing the fracture of nickel-titanium rotary instruments. Int Endod J. 2003;36(4):262-266. 
[22]. Sae-Lim V, Rajamanickam I, Lim BK, et al. Effectiveness of ProFile .04 taper rotary instruments in endodontic retreatment.J Endod. 2000;26(2):100-104.

[23]. Barrieshi-Nusair KM. Gutta-percha retreatment: effectiveness of nickel-titanium rotary instruments versus stainless steel hand files. J Endod. 2002;28(6):454-456.

[24]. Bramante CM, Betti LV. Efficacy of Quantec rotary instruments for gutta-percha removal. Int Endod J. 2000;33(5):463-467. 